\title{
Consideration of fire risks in construction on the basic of territories typology
}

\author{
Vladimir Minaev ${ }^{1}$, Boris Korobets ${ }^{1}$, Tuan $\mathrm{Dao}^{2}$, Phan Tuan $\mathrm{Anh}^{3 *}$ \\ ${ }^{1}$ Bauman Moscow State Technical University, 105005, Baumanskaya 2-ya St., 5/1, Moscow, Russia \\ ${ }^{2}$ The University of Fire Fighting and Prevention, 10000, 243 Khuat Duy Tien, Hanoi, Vietnam \\ ${ }^{3}$ Moscow State University of Civil Engineering, Yaroslavskoe shosse, 26, Moscow, 129337, Russia
}

\begin{abstract}
Subject of the study: The article considers assessments of fire risks in Vietnamese typological clusters. A set of factors characterized by economic, social, demographic, climatic indicators, as well as indicators that take into account processes of urbanization, electrification, trade and transport development, affecting both construction industry functioning and fire services activities in clusters are considered in building typology. Goal of the study: Triune and aimed at territories fire risks typology on the basic of cluster analysis - assessment of territorial differences in fire risks - justification models of optimal management of fire service resources in territorial clusters.

Materials and methods: Methodological basis for fire risks assessment is the integral fire risks theory. Trends for each province in Vietnam from 2006 to 2016, and their averaged indicator for the same years are considered.

Results: In term of fire risks, five homogeneous clusters of provinces are identified.

Conclusions: Obtained typology in Vietnam makes it possible to develop practical recommendations for authorities, industries, including construction one, and fire service, on improving management of territorial resources taking into account fire risks, interaction between regional operational services, enhancing legal and regulatory support for insurance in construction industry.
\end{abstract}

\section{Introduction}

Considering rapid economic growth of many countries in the last decade, fire risks and negative factors have become aggravated, which variously effect on fire safety of their territories, including construction industry with increased number of fires. This necessitated development of new methods and models to analyze, predict and manage fire risks based on modern cluster territorial analysis procedures [1-3].

In turn, typological structures reflecting differences in operational situation for fire service are very much in demand for implementation of principles, scientific basis, management models for optimal distribution of human resources and other resources of the said service, including for the convenience of construction industry [4, 5].

\footnotetext{
${ }^{*}$ Corresponding author: ptuananh26789@ gmail.com
} 
These methods and approaches allow creating a complex of mathematical models that enable:

- $\quad$ purposeful structural and dynamic analysis of temporal and territorial features of fire risks in clusters;

- to forecast main characteristics of fire situation in clusters taking into account the impact of activities of fire service units on it;

- $\quad$ to implement methods of optimal management fire service resources.

All this makes it possible to create a modern complex of new analytical models, algorithms and management tools to improve fire prevention activities, to reduce damage from them, number of deaths and injuries in fires.

Impact of various factors on fire risks is most clearly and definitely seen in rapidly developing economies to which Vietnam belongs [6, 7].

Materials and side of study are chosen due to the following two conditions.

Firstly, since the beginning of the $21^{\text {st }}$ century Vietnam has had a persistently high economic growth (about 7-9\% annually) due to increased energy consumption and urbanization rate of its territories, increase in construction scope, number and scale of industrial sites, processing zones and shopping centers [6].

Secondly, rapid economic development resulted in negative phenomena, including growing number of fires at enterprises, institutions, residential and construction industries. In 2001-2017, there were almost 38 thousand fires in Vietnam, over 1,200 dead and over 3000 injured people; financial loss from fires reached 650 million dollars. Indirect losses were 5-6 times more than direct damage[7].

The scientific problem of complex analysis fire risks solved in the article is connected with construction of typological clusters, identification of differences in fire situation in Vietnamese clusters, justification and statement of problem for optimal management of territorial resource of fire units, including minimizing fire risks in construction industry.

\section{Statement and solution to the problem of territories typology}

The typology of territories on fire risks was solved with regard to the Vietnamese provinces which are very complex and heterogeneous in fire situation.

Statement of problem's territories typology was as follows. Let the $X$ be the set of different territories, and the $Y$ - the set of clusters. Function of the distance between the territories $\rho\left(x_{i}, x_{j}\right)$ is given, where the $i, j$ are territory indices; $i=1, \ldots, n ; j=1, \ldots, n ; n$ is total number of territories $X=\left\{x_{i}\right\}$.

The set of territories $X$ is required to be divided into non-overlapping subsets $Y^{1} \cup Y^{2} \cup$ $\ldots Y^{M}=X$, called clusters $Y^{m},(m=1, \ldots, M)$, in such a way as each cluster is consisted of objects close to the $\rho$ metric, and the objects of different clusters are differed substantially in the same metric. And each object $x_{i} \in X$ is assigned the cluster number $x_{i m} ; m=1, \ldots, M$.

When clustering the territories it was assumed that fire situation indicators were characterized by equal importance factors and standardized as follows:

$$
z_{i j}=\frac{x_{i j}-\bar{x}_{i}}{\sqrt{\sum_{i=1}^{I} \sum_{j=1}^{J}\left(x_{i j}-\bar{x}_{i}\right)^{2}}}
$$

where $x_{i j}$ - the value of the $j$-th fire hazard indicator in the $i$-th province; $I$ is the number of provinces equal to $63 ; J$ - the total number of indicators characterizing fire hazard state; $\bar{x}_{j}$ - the average value of the $j$-th fire hazard indicator.

Following analysis of the factors determining fire risks state in the Vietnameseviet territories, a factor complex for determination of fires in the country [6], reflecting economic, demographic, climatic factors, as well as factors of urbanization, electrification, transport accessibility, trade, associated with fire hazard of facilities, manpower, material 
and technical potential of fire service, prevention and severity of fire consequences is taken for typologization by fire hazard state.

The factor complex was substantiated with the results of selection by expert practitioners and scientists of the indicators most fully characterizing fire risks in the Vietnamese provinces as well as with the results of the papers [6-9].

\section{Results of the study}

The studies with the use of correlation analysis for elimination of highly related indicators (correlation coefficient in absolute terms is greater than 0.85) showed that specific characteristics determining fire risks in residential and economic entities sectors differ intersecting in some part. Trends from 2006 to 2016, as well as their averaged indicator for the same years are considered. When solving typology problem by clustering method with respect to the residential sector, a matrix of 63 provinces, 27 characteristics was considered; when solving the same problem with respect to the economic entities sector, a matrix of 63 provinces, 18 characteristics was considered.

For well-grounded classification of fire service activities by fire risks for typology of Vietnamese territories in homogeneous groups, a problem of their joint clustering per totality of fire hazard characteristics in the economic entities and residential sectors is solved.

Measure of the distance between the clusters and method of provinces clustering was selected by enumeration of the options provided in highly developed Statistica 12 statistical software package. Then, the options were analyzed by the experts. The option where the allocated clusters met three conditions was selected:

- compactness of location on the Vietnamese territory;

- $\quad$ similarity of social and economic conditions and state of operational situation with regard to fire protection defined by similar characteristics of external environment where it functions (density and demographic characteristics of population, climate, fire hazard of economic entities, residential sector and similar factors);

- $\quad$ similarity of fire service manpower and resources parameters.

Among the metrics of distance between the clusters, six options included in the specified software package were investigated: Euclidean distance, squared Euclidean distance, Manhattan distance, Chebyshev distance, Minkowski distance, Pearson correlation coefficient.

Hierarchical (tree-like) procedures of cluster analysis included in the package were used as clustering methods: single-link rule (the nearest neighbor); complete links rule (the most distant neighbors); rule of unweighted pair wise average; rule of weighted pair wise average; unweighted centroid method; weighted centroid method; Ward's rule.

The experts presented 15 options reflecting different combinations of distance metrics and clustering methods. Apparently illogical results of Vietnamese territories typology, which obviously did not meet the above-mentioned conditions of expert analysis, were excluded from consideration.

The experts selected distribution of the Vietnamese provinces by clusters shown in Figure 1. Final complex typology of the territories by fire hazard for all facilities (economic entities plus residential sector) was obtained using the Ward's clustering method with a metric in the form of Manhattan distance. As a result of typology problem solution in Vietnamese territories (provinces and cities of republican subordination) from six regions were distributed into five fairly homogeneous clusters. It almost coincided with territories typology separately for the sectors under consideration (economic entities, residential sector).

Fire situation in the Vietnamese clusters identified as a result of solving the 
multidimensional typology problem is characterized by a complex multidirectional combination of fire indicators, environmental characteristics and provision of fire service with personnel, transport, material and technical resources.

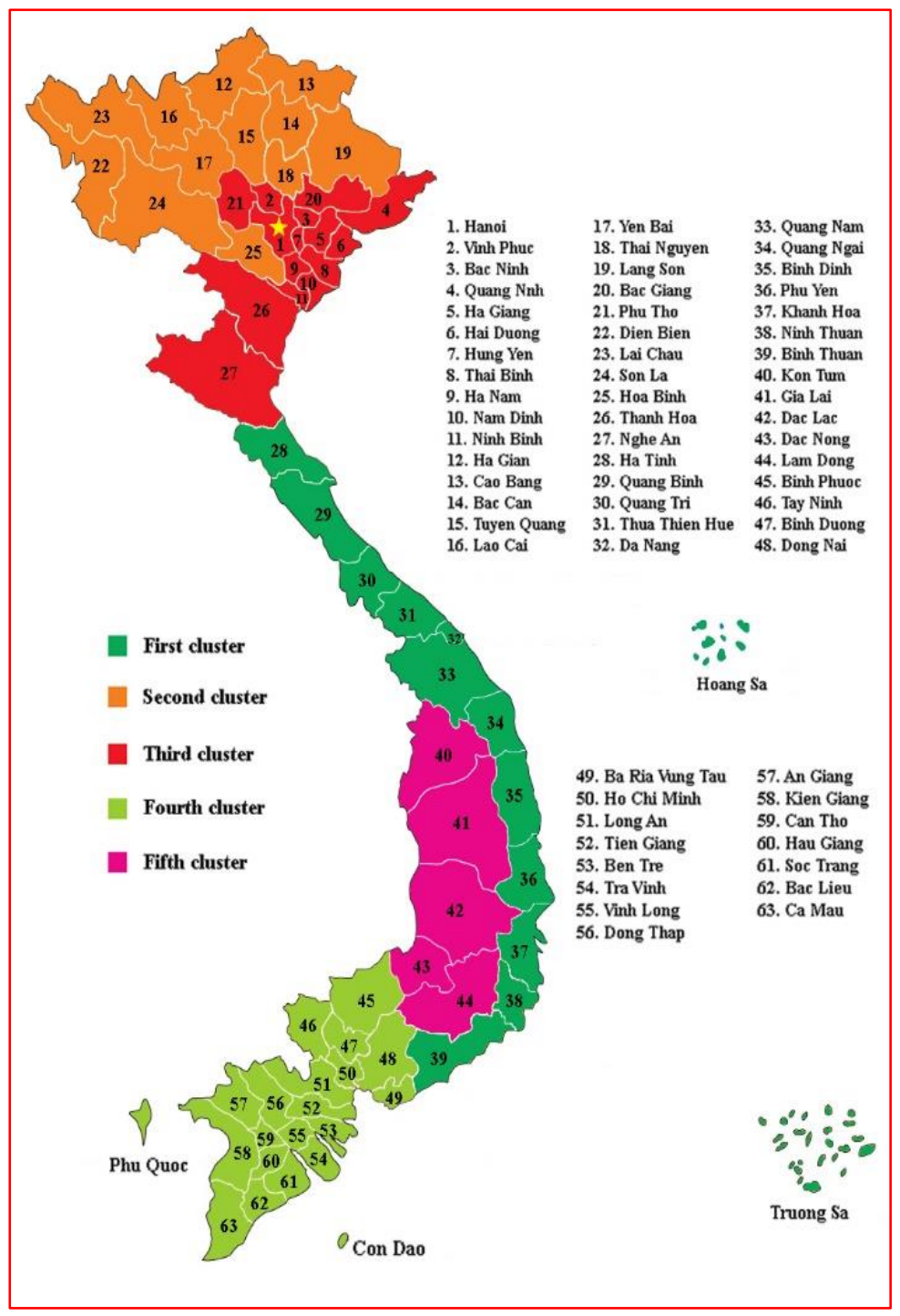

Fig. 1. Complex fire risk typology of the Vietnamese provinces

The analysis showed that integral fire risks $[1,2]$ reflecting deaths and injuries in fires, as well as financial losses resulted from fires differ significantly in typological groups of the territories identified as a result of cluster analysis.

It is evident that the results of the analysis should form a basis for optimal management of fire service resources in both territorial and dynamic aspects.

\section{Conclusions}

Analysis of the typology obtained results in the following conclusions and practical 
recommendations for authorities, branches of economy, including construction, and Vietnamese fire service: clusters 1,2 and 5 were formed only from the provinces of one region - the Central Coast, Northern Midlands and mountain provinces, Central Highlands, respectively; cluster 3 consists of provinces in the HongHa Delta and neighboring provinces (from the Northern Midlands and mountain provinces, Central Coast); cluster 4 is the southern part of Vietnam consisting of 19 provinces located in the Mekong Delta and South-East Region.

Analysis of transformations that occurred as a result of typology and reflecting province transitions between different regions, slightly changes the view of existing administrative division of the Vietnamese territories in terms of fire risk evidence, which certainly should be used in arranging the activities of construction industry and insurance companies serving the construction industry.

Results of typologization as a problem of territories synthesis into homogeneous groups by fire situation make it possible to more effectively solve a whole range of problems related to improving management in construction industry in terms of fire risk consideration, resources of fire service, interaction of regional operational services, including adjacent regions, enhancement of legal support for insurance activities in construction sector and other important tasks.

\section{References}

1. N. Brushlinsky, V. Esin, V. Sluev et al. Fire risks. Issue. 4. Fire risk management. Ed. N. Brushlinsky, N. Shebeko (2006).

2. V. Minaev, N. Topolsky, V. Simakov, I. Teterin, Dao Anh Tuan. The results of the typology of the territories of Vietnam on the characteristics of the fire situation. Technologies of technospheric security No.4 (74) (2017).

3. C. Jennings. Fire Safety Journal . Part A(0), No. 162 ). Pp.13-19. (2013).

4. S. Kachanov., G. Nigmetov Monitoring of territories, buildings and structures to improve the reliability of results in an independent risk assessment. Civil Safety Technologies, No.3. Pp. 40-45. (2009).

5. N. Benichou., A. Kashef. How to Use Fire Risk Assessment Tools to Evaluate Performance-Based Designs. CIB World Building Congress. Pp. 1-11. (2004)

6. V. Minaev, N. Topolsky, Dao Anh Tuan. Problems and main factors of fire risk assessment in Vietnam. Technologies of technospheric security No.1 (65) (2016)

7. . V. Minaev, N. Topolsky, Dao Anh Tuan. Information support of the task of typology of Vietnam territories in the fire situation. Technologies of technospheric security No.1 (71) (2017)

8. J. Xin, C. Huang. Fire risk analysis of residential buildings based on scenario clusters and its application in fire risk management. Fire Safety Journal. . No. 62. Part A(0) (2013).

9. S. Yakush, R. Esmanskii. Analysis of fire risks. Part I: Approaches and methods / Problems of risk analysis. Volume 6. No. 3. Pp. 8-27. (2009). 